\title{
A literature-based systematic HuGE review and meta-analysis show that CASP gene family polymorphisms are associated with risk of lung cancer
}

\author{
Z.Y. Zhang, Y. Xuan, X.Y. Jin, X. Tian and R. Wu \\ Department of Medical Oncology, \\ Shengjing Affiliated Hospital of China Medical University, \\ Shenyang, Liaoning, China \\ Corresponding author: Z.Y. Zhang \\ E-mail: cmuzhangzy@163.com
}

Genet. Mol. Res. 12 (3): 3057-3069 (2013)

Received May 11, 2012

Accepted September 13, 2012

Published January 4, 2013

DOI http://dx.doi.org/10.4238/2013.January.4.22

\begin{abstract}
The caspase (CASP) gene family is known to be involved in apoptosis, cytokine maturation, cell growth, and differentiation. A large number of single nucleotide polymorphisms (SNPs) in the CASP gene family have been increasingly recognized as important regulators in the development of lung cancer. However, this specific association is still controversial. In this Human Genome Epidemiology review and meta-analysis, we summarized the available evidence associating lung cancer with the CASP gene family. Seven studies, which included 1155 lung cancer cases and 1120 healthy controls, met the inclusion criteria and were included in our meta-analysis. In seven studies, 19 different SNPs have been studied in seven CASP genes, including CASP-1, -2, $-5,-7,-8,-9$, and -10 . Meta-analysis results showed positive associations between heterozygote $(\mathrm{A} / \mathrm{G})$ of rs507879 in the CASP-5 gene, the T allele of rs12415607 in the CASP-7 gene, and the $\mathrm{T}$ allele and $\mathrm{T}$ carrier $(\mathrm{C} / \mathrm{T}+\mathrm{T} / \mathrm{T})$ of rs4645981 in the CASP-9 gene with lung cancer susceptibility [odds ratio $(\mathrm{OR})=1.83,95 \%$ confidence interval $(95 \% \mathrm{CI})$
\end{abstract}


$=1.07-3.12, \mathrm{P}=0.03 ; \mathrm{OR}=1.18,95 \% \mathrm{CI}=1.02-1.37, \mathrm{P}=0.03 ; \mathrm{OR}=$ $1.43,95 \% \mathrm{CI}=1.12-1.81, \mathrm{P}=0.004 ; \mathrm{OR}=1.46,95 \% \mathrm{CI}=1.10-1.93$, $\mathrm{P}=0.009$; respectively]. However, we found that homozygote $(\mathrm{G} / \mathrm{G})$ of rs2227310 in the CASP-7 gene, del allele, heterozygote (ins/del), and del carrier (ins/del + del/del) of rs3834129 in CASP-8 could be protective factors for lung cancer $(\mathrm{OR}=0.17,95 \% \mathrm{CI}=0.14-0.21, \mathrm{P}=$ $0.0003 ; \mathrm{OR}=0.83,95 \% \mathrm{CI}=0.72-0.97, \mathrm{P}=0.02 ; \mathrm{OR}=0.74,95 \% \mathrm{CI}$ $=0.64-0.85, \mathrm{P}<0.0001 ; \mathrm{OR}=0.81,95 \% \mathrm{CI}=0.71-0.93, \mathrm{P}=0.002$; respectively). In conclusion, based on this meta-analysis, we suggest that SNPs in CASP-5, $-7,-8$, and -9 are associated with susceptibility to lung cancer.

Key words: Caspase; Gene polymorphisms; Lung cancer; Meta-analysis

\section{INTRODUCTION}

Lung cancer (LC), characterized by uncontrolled cell growth in tissues of the lung (D'Amico et al., 2010), is one of the most common malignant tumors, representing a significant threat to human health (Han et al., 2011). According to the statistics collected by WHO, every year around 1.10 million people die from LC (Long et al., 2008). LC is the leading cause of cancer death in the United States, and has a 5-year relative survival rate of only $16 \%$ (Stewart, 2010). There are two main pathological types of LC, namely small-cell lung cancer (SCLC) and non-small-cell lung cancer (NSCLC) (Bandi et al., 2009). NSCLC is the most common form of LC, where about $85 \%$ of cancers are classified as NSCLC, while SCLC occurs in approximately $13-15 \%$ of patients (Wood et al., 2012). Those who suffer from LC may be afflicted with shortness of breath, coughing (including coughing up blood), and weight loss (Zhao et al., 2010). LC is caused by both genetic and environmental factors and their interactions, and susceptibility differences in the form of rare high-penetrance genes and genetic polymorphism (Vaissière et al., 2009).

Caspases (CASP), with 14 known members, comprise a family characterized by highly conserved intracellular aspartate-specific cysteine proteases (Van De Water et al., 2004; Mittal et al., 2011). Two types are recognized in the CASP family: initiator caspases and effector caspases. CASP-2, -8, -9, -10 are initiator caspases and CASP-3, -6, -7 are executioner caspases (Yu et al., 2009). CASP-4 and -5 are not currently classified as initiator or effector, because they are inflammatory enzymes that, in concert with CASP-1, are involved in T-cell maturation (Van De Water et al., 2004). CASP-14 is not involved in apoptosis or inflammation, but instead is involved in skin cell development (Yu et al., 2009). Studies have shown that the CASP gene family plays an important role in executing cell apoptosis (Du et al., 2005). CASP causes cell death by nuclear membrane breakdown, DNA fragmentation, and chromatin condensation, and the formation of apoptotic genetic polymorphisms for genes controlling the cell cycle or apoptosis has been found to increase the risk for a number of human malignancies (Theodoropoulos et al., 2011). Single nucleotide polymorphisms (SNPs) are the most common form of human genetic variation and may lead to an individual's susceptibility to cancer. Recently, a large number of SNPs in the CASP apoptotic pathway have been increasingly rec- 
ognized. Several studies have demonstrated that some variants in apoptosis pathway genes are associated with the susceptibility to various human cancers, especially LC (MacPherson et al., 2004; Zhang et al., 2005; Kesarwani et al., 2011). However, this specific association of CASP gene polymorphisms with LC susceptibility remains controversial. Therefore, we performed a Human Genome Epidemiology (HuGE) review and meta-analysis by including the most recent and relevant articles to identify statistical evidence of the associations between CASP gene family polymorphisms and risk of LC that have been investigated.

\section{MATERIAL AND METHODS}

\section{Literature search}

PubMed, Cochrane Library, Embase, Web of Science, Springerlink, CNKI, and CBM databases were searched (last search was updated on April 27, 2012) extensively to identify relevant studies, using the following queries: ["caspase" or "CASP" or "CASPASE" (Mesh)] and ["SNPs" or "SNP" or "polymorphism, genetic" (Mesh)] and ["lung cancer" or "lung tumor" or "lung neoplasms" (Mesh)]. The references in the eligible studies or textbooks were also checked.

\section{Inclusion and exclusion criteria}

The included studies had to meet the following criteria: i) the type of study was a case-control study; ii) the study focused on associations between CASP gene family polymorphisms and LC susceptibility; iii) all patients had a diagnosis of LC confirmed by pathological examination of the surgical specimen; iv) the frequencies of alleles or genotypes in case and control groups could be extracted; v) the publication was in English or Chinese. Studies were excluded when they were: i) not case-control studies about CASP gene family polymorphisms and LC susceptibility; ii) case reports, letters, reviews, and editorial articles; iii) studies that were based on incomplete data; useless or overlapping data were reported; iv) duplicate data were contained in the studies.

\section{Data extraction}

Using a standardized form, data from the studies published were extracted independently by two reviewers (Z.Y.Z. and Y.X.) to populate the necessary information. The following information extracted from each of the articles included: first author, year of publication, country, language, ethnicity, study design, diagnostic criteria, source of cases and controls, number of cases and controls, mean age, sample, pathological types, detection methods, polymorphism genotype frequency, and evidence of Hardy-Weinberg equilibrium (HWE) in controls. In case of conflicting evaluations, an agreement was reached following a discussion with a third reviewer (R.W.).

\section{Quality assessment of the studies included}

Two reviewers (X.Y.J. and X.T.) independently assessed the quality of papers according to modified STROBE quality score systems (Son et al., 2006; Zhang et al., 2011). Forty 
assessment items related to quality appraisal were used in this meta-analysis, with scores ranging from 0 to 40 . Scores of 0-20, 20-30, and 30-40 were defined as low, moderate and high quality, respectively. Disagreement was resolved by discussion with a third reviewer (R.W.).

\section{Statistical analysis}

Allele or genotype frequencies of the SNPs of CASP gene family from the relevant studies were determined by the allele counting method. The odds ratio (OR) and $95 \%$ confidence interval $(95 \% \mathrm{CI})$ were calculated using Review Manager Version 5.1.6 (provided by the Cochrane Collaboration, available at: http://ims.cochrane.org/revman/download) and the STATA Version 12.0 software (Stata Corp., College Station, TX, USA). Between-study variations and heterogeneities were estimated using the Cochran Q-statistic (Higgins and Thompson, 2002; Zintzaras and Ionnidis, 2005) $(\mathrm{P} \leq 0.05$ was considered to be a manifestation of statistically significant heterogeneity). We also quantified the effect of heterogeneity by using the $\mathrm{I}^{2}$ test. $\mathrm{I}^{2}$ ranges between 0 and $100 \%$ and represents the proportion of inter-study variability that can be attributed to heterogeneity rather than chance. $I^{2}$ values of 25,50 , and $75 \%$ were defined as low, moderate, and high estimates, respectively. When a significant Q-test ( $\mathrm{P}$ $<0.10$ ) or $\mathrm{I}^{2}>50 \%$ indicated heterogeneity across studies, the random-effect model was used for meta-analysis, or else the fixed-effect model was used (Viechtbauer, 2007). To establish the effect of heterogeneity on conclusions of meta-analyses, subgroup analysis was performed. We tested whether genotype frequencies of controls were in HWE using the $\chi^{2}$ test. Subgroup analysis based on nationality was used to explore and to explain the diversity among the results of different studies. Sensitivity analysis was mainly performed by sequential omission of individual studies. Publication bias was investigated by Begger's funnel plot, and funnel plot asymmetry was assessed by the Egger linear regression test (Peters et al., 2006), where statistical significance was considered when $\mathrm{P}<0.05$. All the $\mathrm{P}$ values were two-sided. To ensure the reliability and the accuracy of the results, two reviewers (Z.Y.Z. and Y.X.) independently populated the data in the statistics software programs and got the same results.

\section{RESULTS}

\section{Characteristics of the studies included}

The search strategy retrieved 94 potentially relevant studies. According to the inclusion criteria, 7 studies (Park et al., 2006; Son et al., 2006; Lou et al., 2007; Sun et al., 2007; Lee et al., 2009; Ulybina et al., 2009; Hart et al., 2011) were included and 87 were excluded in this meta-analysis. The flow chart of study selection is shown in Figure 1. These 7 case-control studies selected included a total of 1155 LC cases and 1120 healthy controls. All studies were case-control studies, which evaluated the association of CASP gene family polymorphisms and LC susceptibility. The publication year of the studies included ranged from 2006 to 2010. All patients fulfilled the diagnosis criteria of LC confirmed by pathological examination of the surgical specimen. The source of controls was based on a healthy population. The HWE test was performed on the genotype distribution of the controls in all the studies included, and all of them were found to be in HWE (P > 0.05). Seven CASP genes with 19 SNPs were addressed, including CASP-1 (rs501192), CASP-2 (rs4647297), CASP-5 (rs507879, rs523104), 
CASP-7 (rs12415607, rs1593766, rs2227310, rs10787498), CASP-8 (rs3834129, rs3769818, rs1045485), CASP-9 (rs4645978, rs4645980, rs4645981, rs4645982, rs1052571, rs1052576, rs2308950), and CASP-10 (rs13006529). All quality scores of the studies included were higher than 20 (moderate to high quality). The baseline characteristics and methodological quality of all the studies included are summarized in Table 1. The genotype distribution and risk allele frequency are summarized in Table 2.

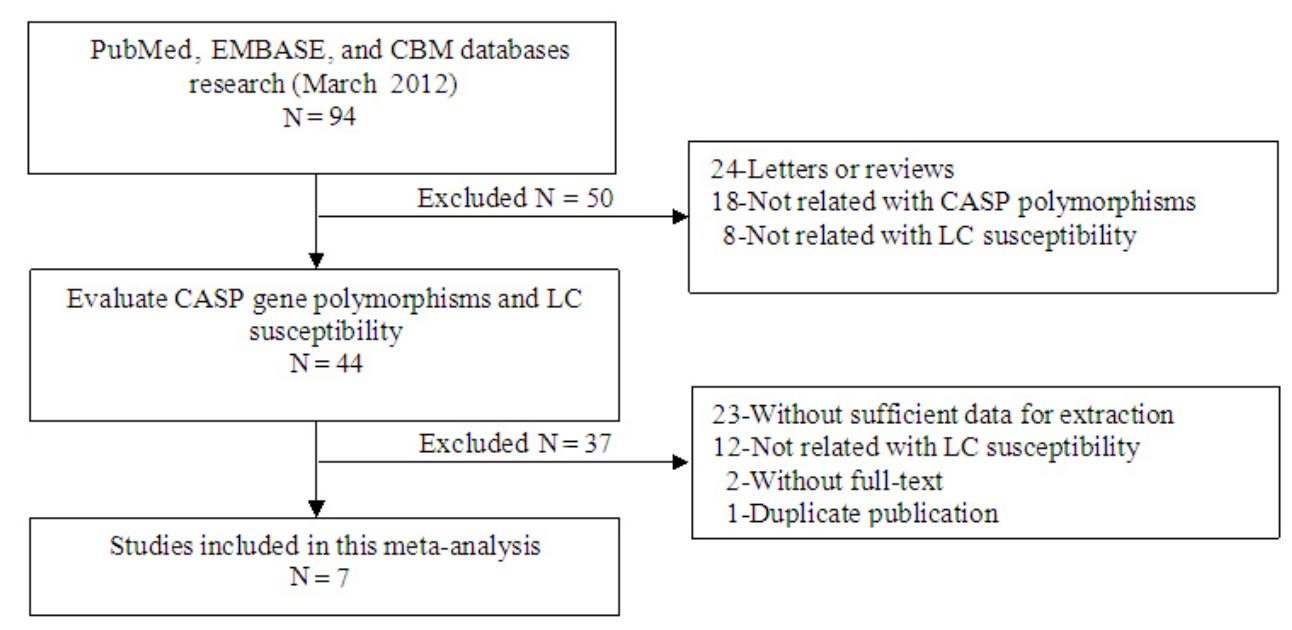

Figure 1. Flow chart shows study selection procedure. $\mathrm{CASP}=$ caspase; $\mathrm{LC}=$ lung cancer.

\section{Association between CASP gene family polymorphisms and LC risk}

A summary of the meta-analysis findings of the association between CASP gene family polymorphisms and LC susceptibility is provided in Table 3 . The meta-analysis results showed that the heterozygote $(\mathrm{A} / \mathrm{G})$ of $\mathrm{rs} 507879$ in the CASP-5 gene was positively associated with $\mathrm{LC}$ risk $(\mathrm{OR}=1.83,95 \% \mathrm{CI}=1.07-3.12, \mathrm{P}=0.03)$. In addition, the $\mathrm{T}$ allele of rs12415607 in the CASP-7 gene also showed a significantly positive association with LC susceptibility (OR $=1.18,95 \% \mathrm{CI}=1.02-1.37, \mathrm{P}=0.03)$. However, the homozygote $(\mathrm{G} / \mathrm{G})$ of $\mathrm{rs} 2227310$ in the CASP-7 gene showed a negative relation to LC susceptibility $(\mathrm{OR}=0.17,95 \% \mathrm{CI}=0.14-0.21$, $\mathrm{P}=0.0003)$. Similarly, the del allele, heterozygote (ins/del), and del carrier (ins/del $+\mathrm{del} / \mathrm{del}$ ) of rs3834129 in CASP-8 also showed a negative association with $\mathrm{LC}$ risk $(\mathrm{OR}=0.83,95 \% \mathrm{CI}=$ $0.72-0.97, \mathrm{P}=0.02 ; \mathrm{OR}=0.74,95 \% \mathrm{CI}=0.64-0.85, \mathrm{P}<0.0001 ; \mathrm{OR}=0.81,95 \% \mathrm{CI}=0.71-0.93$, $\mathrm{P}=0.002$, respectively). Only the $\mathrm{T}$ allele and $\mathrm{T}$ carrier $(\mathrm{C} / \mathrm{T}+\mathrm{T} / \mathrm{T})$ of $\mathrm{rs} 4645981$ in the CASP-9 gene showed a positive association with $\mathrm{LC}$ risk $(\mathrm{OR}=1.43,95 \% \mathrm{CI}=1.12-1.81, \mathrm{P}=0.004$; OR $=1.46,95 \% \mathrm{CI}=1.10-1.93, \mathrm{P}=0.009$, respectively). On the other hand, there was no significant associations found between CASP-1 (rs501192), CASP-2 (rs4647297), CASP-5 (rs523104), CASP-7 (rs1593766, rs2227310), CASP-8 (rs3769818, rs1045485), CASP-9 (rs4645978, rs4645980, rs4645982, rs1052571, rs1052576, rs2308950), and CASP-10 (rs13006529) (all P $>0.05$ ) and LC risk. Sensitivity analysis was performed by sequential omission of each study. The significance of pooled OR in all individual analyses and subgroup analyses was not influenced excessively by omitting any single study. 


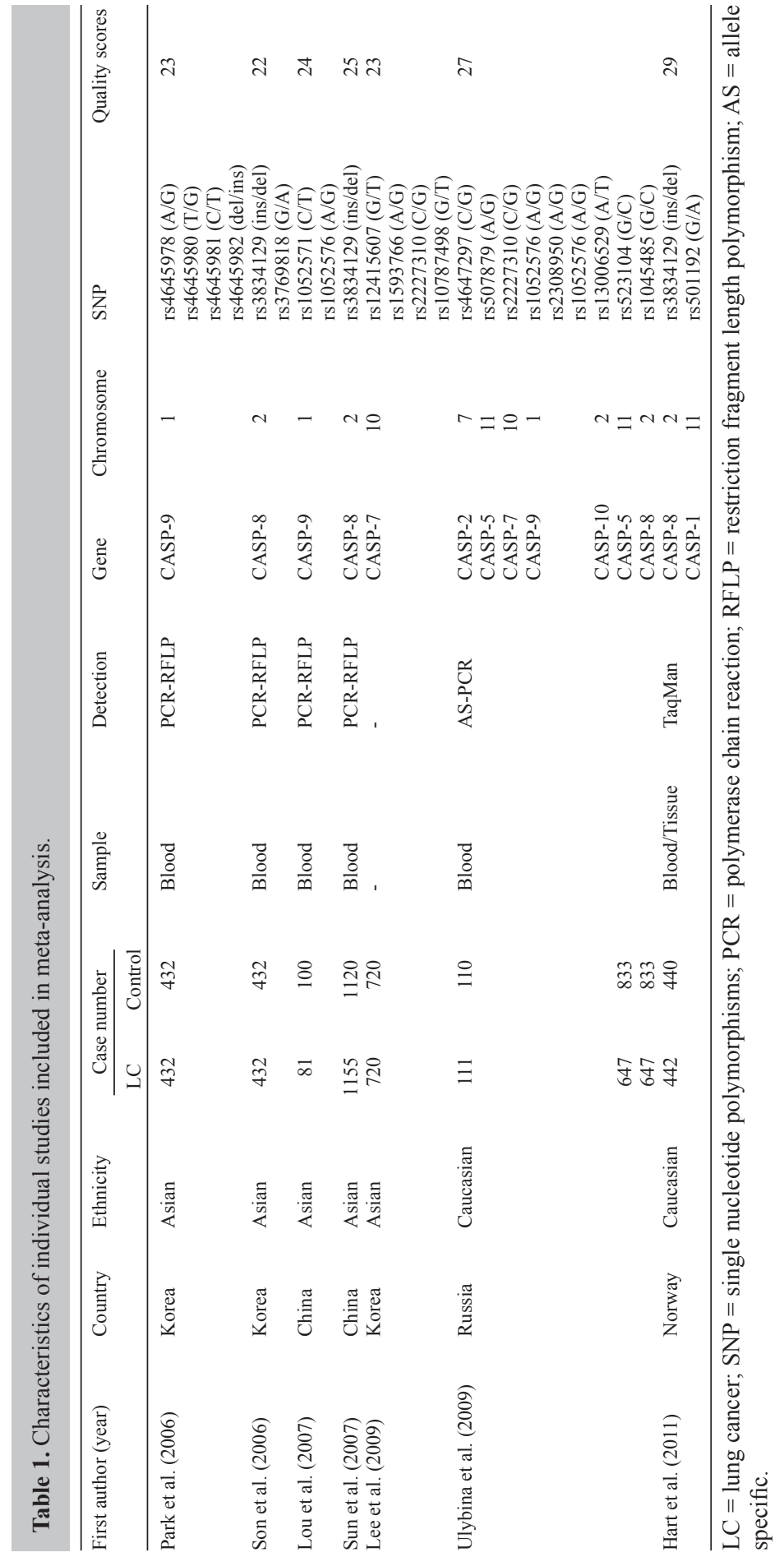




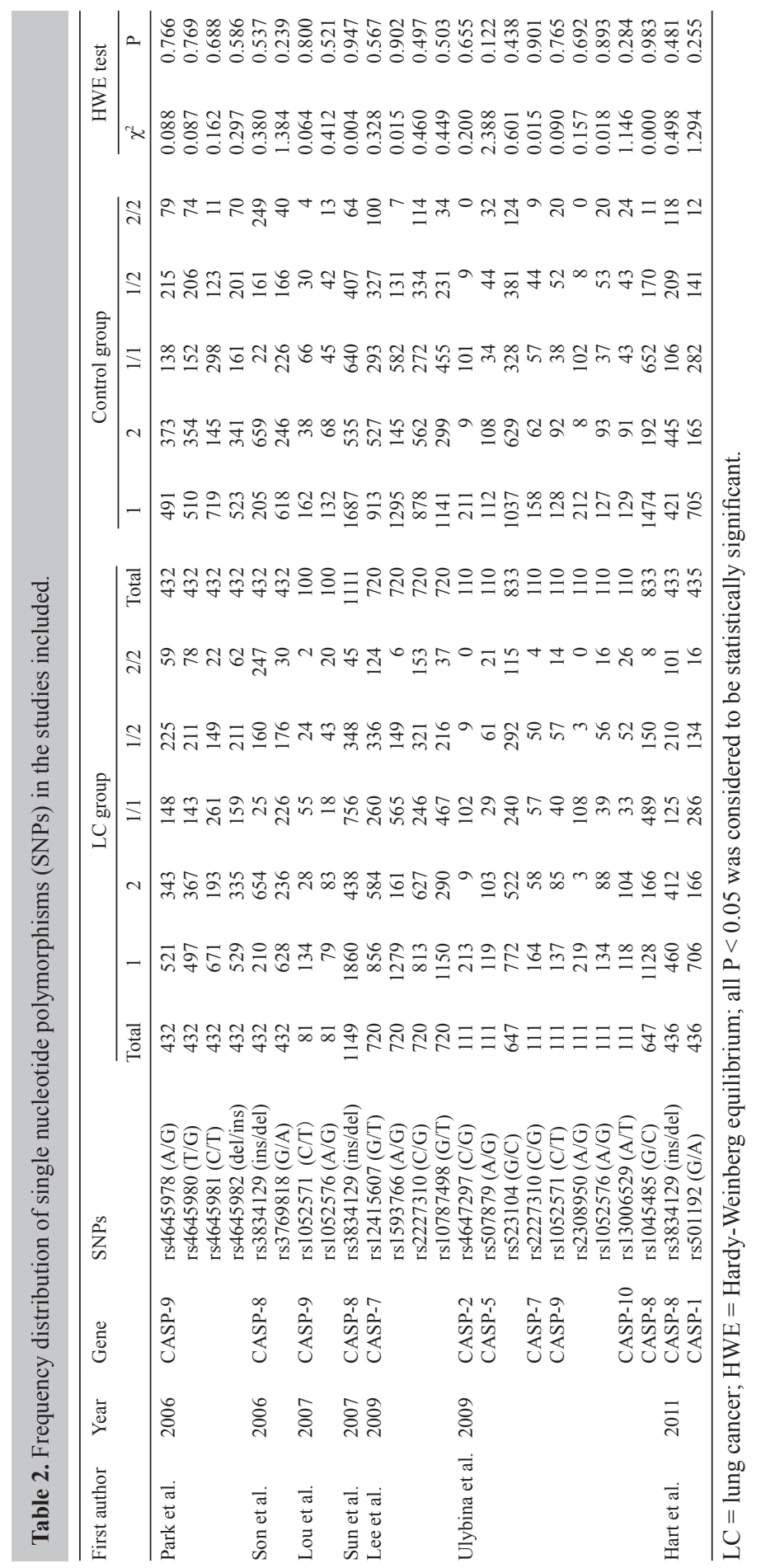


Table 3. Meta-analysis of the association between CASP gene polymorphisms and lung cancer (LC).

\begin{tabular}{|c|c|c|c|c|c|c|}
\hline Polymorphisms & & LC (cases n/N) & Controls $(\mathrm{n} / \mathrm{N})$ & OR $(95 \% \mathrm{CI})$ & $\mathrm{P}$ & Effect model \\
\hline \multicolumn{7}{|l|}{ CASP-1 } \\
\hline \multirow[t]{4}{*}{ Rs501192 } & A allele & $166 / 872$ & $165 / 870$ & $1.00(0.79-1.28)$ & 0.97 & Fixed \\
\hline & $\mathrm{G} / \mathrm{A}+\mathrm{A} / \mathrm{A}$ & $150 / 436$ & $153 / 435$ & $0.97(0.73-1.28)$ & 0.81 & Fixed \\
\hline & $\mathrm{A} / \mathrm{A}$ & $16 / 436$ & $12 / 435$ & $1.34(0.63-2.87)$ & 0.45 & Fixed \\
\hline & $\mathrm{G} / \mathrm{A}$ & $134 / 436$ & $141 / 435$ & $0.93(0.70-1.23)$ & 0.59 & Fixed \\
\hline \multicolumn{7}{|l|}{ CASP-2 } \\
\hline \multirow[t]{4}{*}{ Rs4647297 } & G allele & $9 / 222$ & $9 / 220$ & $0.99(0.39-2.54)$ & 0.98 & Fixed \\
\hline & $\mathrm{C} / \mathrm{G}+\mathrm{G} / \mathrm{G}$ & $9 / 111$ & $9 / 110$ & $0.99(0.38-2.60)$ & 0.98 & Fixed \\
\hline & $\mathrm{G} / \mathrm{G}$ & - & - & - & - & - \\
\hline & $\mathrm{C} / \mathrm{G}$ & $9 / 111$ & $9 / 110$ & $0.99(0.38-2.60)$ & 0.98 & Fixed \\
\hline \multicolumn{7}{|l|}{ CASP-5 } \\
\hline \multirow[t]{4}{*}{ Rs507879 } & $\mathrm{G}$ allele & $103 / 222$ & $108 / 220$ & $0.90(0.62-1.30)$ & 0.57 & Fixed \\
\hline & $\mathrm{A} / \mathrm{G}+\mathrm{G} / \mathrm{G}$ & $82 / 111$ & $76 / 110$ & $1.26(0.70-2.27)$ & 0.43 & Fixed \\
\hline & $\mathrm{G} / \mathrm{G}$ & $21 / 111$ & $32 / 110$ & $0.57(0.30-1.07)$ & 0.08 & Fixed \\
\hline & $\mathrm{A} / \mathrm{G}$ & $61 / 111$ & $44 / 110$ & $1.83(1.07-3.12)$ & 0.03 & Fixed \\
\hline \multirow[t]{4}{*}{ Rs523104 } & $\mathrm{C}$ allele & $522 / 1294$ & $629 / 1666$ & $1.11(0.96-1.29)$ & 0.15 & Fixed \\
\hline & $\mathrm{G} / \mathrm{C}+\mathrm{C} / \mathrm{C}$ & $407 / 647$ & $505 / 833$ & $1.10(0.89-1.36)$ & 0.37 & Fixed \\
\hline & $\mathrm{C} / \mathrm{C}$ & $115 / 647$ & $124 / 833$ & $1.24(0.94-1.63)$ & 0.13 & Fixed \\
\hline & $\mathrm{G} / \mathrm{C}$ & $292 / 647$ & $381 / 833$ & $0.98(0.79-1.20)$ & 0.82 & Fixed \\
\hline \multicolumn{7}{|l|}{ CASP-7 } \\
\hline \multirow[t]{4}{*}{ Rs12415607 } & $\mathrm{T}$ allele & $584 / 1440$ & $527 / 1440$ & $1.18(1.02-1.37)$ & 0.03 & Fixed \\
\hline & $\mathrm{G} / \mathrm{T}+\mathrm{T} / \mathrm{T}$ & $460 / 720$ & $427 / 720$ & $1.21(0.98-1.50)$ & 0.07 & Fixed \\
\hline & $\mathrm{T} / \mathrm{T}$ & $124 / 720$ & $100 / 720$ & $1.29(0.97-1.72)$ & 0.08 & Fixed \\
\hline & $\mathrm{G} / \mathrm{T}$ & $336 / 720$ & $327 / 720$ & $1.05(0.85-1.29)$ & 0.63 & Fixed \\
\hline \multirow[t]{4}{*}{ Rs1593766 } & G allele & $161 / 1440$ & $145 / 1440$ & $1.12(0.89-1.43)$ & 0.33 & Fixed \\
\hline & $\mathrm{A} / \mathrm{G}+\mathrm{G} / \mathrm{G}$ & $155 / 720$ & $138 / 720$ & $1.16(0.89-1.50)$ & 0.27 & Fixed \\
\hline & $\mathrm{G} / \mathrm{G}$ & $6 / 720$ & $7 / 720$ & $0.86(0.29-2.56)$ & 0.78 & Fixed \\
\hline & $\mathrm{A} / \mathrm{G}$ & $149 / 720$ & $131 / 720$ & $1.17(0.90-1.52)$ & 0.23 & Fixed \\
\hline \multirow[t]{4}{*}{ Rs2227310 } & G allele & $685 / 1662$ & $624 / 1660$ & $1.12(0.87-1.43)$ & 0.39 & Fixed \\
\hline & $\mathrm{C} / \mathrm{G}+\mathrm{G} / \mathrm{G}$ & $528 / 831$ & $501 / 830$ & $1.15(0.94-1.40)$ & 0.18 & Fixed \\
\hline & $\mathrm{G} / \mathrm{G}$ & $157 / 831$ & $457 / 830$ & $0.17(0.14-0.21)$ & 0.0003 & Random \\
\hline & $\mathrm{C} / \mathrm{G}$ & $371 / 831$ & $492 / 830$ & $0.75(0.30-1.85)$ & 0.53 & Random \\
\hline \multirow[t]{4}{*}{ Rs10787498 } & $\mathrm{T}$ allele & $290 / 1440$ & $299 / 1440$ & $0.96(0.80-1.15)$ & 0.68 & Fixed \\
\hline & $\mathrm{G} / \mathrm{T}+\mathrm{T} / \mathrm{T}$ & $253 / 720$ & $265 / 720$ & $0.93(0.75-1.15)$ & 0.51 & Fixed \\
\hline & $\mathrm{T} / \mathrm{T}$ & $37 / 720$ & $34 / 720$ & $1.09(0.68-1.76)$ & 0.72 & Fixed \\
\hline & $\mathrm{G} / \mathrm{T}$ & $216 / 720$ & $231 / 720$ & $0.91(0.73-1.13)$ & 0.39 & Fixed \\
\hline \multicolumn{7}{|l|}{ CASP-8 } \\
\hline \multirow[t]{4}{*}{ Rs3834129 } & del allele & $1504 / 4034$ & $1639 / 1639$ & $0.83(0.72-0.97)$ & 0.02 & Random \\
\hline & ins $/ \mathrm{del}+\mathrm{del} / \mathrm{del}$ & $1111 / 2017$ & $1208 / 1976$ & $0.74(0.64-0.85)$ & $<0.0001$ & Fixed \\
\hline & $\mathrm{del} / \mathrm{del}$ & $393 / 2017$ & $431 / 1976$ & $0.84(0.71-1.01)$ & 0.06 & Fixed \\
\hline & ins/del & $819 / 2017$ & $895 / 1976$ & $0.81(0.71-0.93)$ & 0.002 & Fixed \\
\hline \multirow[t]{4}{*}{ Rs3769818 } & A allele & $236 / 864$ & $246 / 864$ & $0.94(0.77-1.17)$ & 0.59 & Fixed \\
\hline & $\mathrm{G} / \mathrm{A}+\mathrm{A} / \mathrm{A}$ & $206 / 432$ & $206 / 432$ & $1.00(0.77-1.31)$ & 0.11 & Fixed \\
\hline & $\mathrm{A} / \mathrm{A}$ & $30 / 432$ & $40 / 432$ & $0.73(0.45-1.20)$ & 0.21 & Fixed \\
\hline & $\mathrm{G} / \mathrm{A}$ & $176 / 432$ & $166 / 432$ & $1.10(0.84-1.45)$ & 0.49 & Fixed \\
\hline \multirow[t]{4}{*}{ Rs1045485 } & $\mathrm{C}$ allele & $166 / 1294$ & $192 / 1666$ & $1.13(0.91-1.41)$ & 0.28 & Fixed \\
\hline & $\mathrm{G} / \mathrm{C}+\mathrm{C} / \mathrm{C}$ & $158 / 647$ & $181 / 833$ & $1.16(0.91-1.48)$ & 0.22 & Fixed \\
\hline & $\mathrm{C} / \mathrm{C}$ & $8 / 647$ & $11 / 833$ & $0.94(0.37-2.34)$ & 0.89 & Fixed \\
\hline & $\mathrm{G} / \mathrm{C}$ & $150 / 647$ & $170 / 833$ & $1.18(0.92-1.51)$ & 0.20 & Fixed \\
\hline
\end{tabular}

Continued on next page 


\section{Table 3. Continued.}

\begin{tabular}{|c|c|c|c|c|c|c|}
\hline \multicolumn{2}{|l|}{ Polymorphisms } & \multirow[t]{2}{*}{$\mathrm{LC}$ cases $\mathrm{n} / \mathrm{N}$} & \multirow[t]{2}{*}{ Controls n/N } & \multirow[t]{2}{*}{ OR $(95 \% \mathrm{CI})$} & \multirow[t]{2}{*}{$\mathrm{P}$} & \multirow[t]{2}{*}{ Effect model } \\
\hline CASP-9 & & & & & & \\
\hline \multirow[t]{4}{*}{ Rs4645978 } & G allele & $343 / 864$ & $373 / 864$ & $0.87(0.72-1.05)$ & 0.14 & Fixed \\
\hline & $\mathrm{A} / \mathrm{G}+\mathrm{G} / \mathrm{G}$ & $284 / 432$ & $294 / 432$ & $0.90(0.68-1.20)$ & 0.47 & Fixed \\
\hline & $\mathrm{G} / \mathrm{G}$ & $59 / 432$ & $79 / 432$ & $0.71(0.49-1.02)$ & 0.06 & Fixed \\
\hline & $\mathrm{A} / \mathrm{G}$ & $225 / 432$ & $215 / 432$ & $1.10(0.84-1.43)$ & 0.50 & Fixed \\
\hline \multirow[t]{4}{*}{ Rs4645980 } & G allele & $367 / 864$ & $354 / 864$ & $1.06(0.88-1.29)$ & 0.53 & Fixed \\
\hline & $\mathrm{T} / \mathrm{G}+\mathrm{G} / \mathrm{G}$ & $289 / 432$ & $280 / 432$ & $1.10(0.83-1.45)$ & 0.52 & Fixed \\
\hline & $\mathrm{G} / \mathrm{G}$ & $78 / 432$ & $74 / 432$ & $1.07(0.75-1.51)$ & 0.72 & Fixed \\
\hline & $\mathrm{T} / \mathrm{G}$ & $211 / 432$ & $206 / 432$ & $1.05(0.80-1.37)$ & 0.73 & Fixed \\
\hline \multirow[t]{4}{*}{ Rs4645981 } & $\mathrm{T}$ allele & $193 / 864$ & $145 / 864$ & $1.43(1.12-1.81)$ & 0.004 & Fixed \\
\hline & $\mathrm{C} / \mathrm{T}+\mathrm{T} / \mathrm{T}$ & $171 / 432$ & $134 / 432$ & $1.46(1.10-1.93)$ & 0.009 & Fixed \\
\hline & $\mathrm{T} / \mathrm{T}$ & $22 / 432$ & $11 / 432$ & $2.05(0.98-4.29)$ & 0.06 & Fixed \\
\hline & $\mathrm{C} / \mathrm{T}$ & $149 / 432$ & $123 / 432$ & $1.32(0.99-1.76)$ & 0.06 & Fixed \\
\hline \multirow[t]{4}{*}{ Rs4645982 } & ins allele & $335 / 864$ & $341 / 864$ & $0.97(0.80-1.18)$ & 0.77 & Fixed \\
\hline & $\mathrm{del} / \mathrm{ins}+\mathrm{ins} / \mathrm{ins}$ & $273 / 432$ & $271 / 432$ & $1.02(0.77-1.34)$ & 0.89 & Fixed \\
\hline & ins/ins & $62 / 432$ & $70 / 432$ & $0.87(0.60-1.26)$ & 0.45 & Fixed \\
\hline & del/ins & $211 / 432$ & $201 / 432$ & $1.10(0.84-1.43)$ & 0.50 & Fixed \\
\hline \multirow[t]{4}{*}{ Rs1052571 } & $\mathrm{T}$ allele & $113 / 384$ & $130 / 420$ & $0.87(0.64-1.19)$ & 0.39 & Fixed \\
\hline & $\mathrm{C} / \mathrm{T}+\mathrm{T} / \mathrm{T}$ & 97/192 & $106 / 210$ & $0.93(0.61-1.40)$ & 0.72 & Fixed \\
\hline & $\mathrm{T} / \mathrm{T}$ & $16 / 192$ & $24 / 210$ & $0.64(0.33-1.27)$ & 0.20 & Fixed \\
\hline & $\mathrm{C} / \mathrm{T}$ & $81 / 192$ & $82 / 210$ & $1.09(0.73-1.64)$ & 0.66 & Fixed \\
\hline \multirow[t]{4}{*}{ Rs 1052576} & G allele & $171 / 384$ & $161 / 420$ & $1.34(0.60-3.01)$ & 0.47 & Random \\
\hline & $\mathrm{A} / \mathrm{G}+\mathrm{G} / \mathrm{G}$ & $135 / 192$ & $128 / 210$ & $1.61(0.54-4.83)$ & 0.39 & Random \\
\hline & $\mathrm{G} / \mathrm{G}$ & $36 / 192$ & $33 / 210$ & $1.28(0.45-3.62)$ & 0.65 & Random \\
\hline & $\mathrm{A} / \mathrm{G}$ & $99 / 192$ & $95 / 210$ & $1.28(0.87-1.90)$ & 0.21 & Fixed \\
\hline \multirow[t]{4}{*}{ Rs2308950 } & G allele & $3 / 222$ & $8 / 220$ & $0.36(0.10-1.39)$ & 0.14 & Fixed \\
\hline & $\mathrm{A} / \mathrm{G}+\mathrm{G} / \mathrm{G}$ & $3 / 111$ & $8 / 110$ & $0.35(0.09-1.37)$ & 0.13 & Fixed \\
\hline & $\mathrm{G} / \mathrm{G}$ & - & - & - & - & - \\
\hline & $\mathrm{A} / \mathrm{G}$ & $3 / 111$ & $8 / 110$ & $0.35(0.09-1.37)$ & 0.13 & Fixed \\
\hline \multicolumn{7}{|l|}{ CASP-10 } \\
\hline \multirow[t]{4}{*}{ Rs13006529 } & $\mathrm{T}$ allele & $104 / 222$ & $91 / 220$ & $1.25(0.86-1.82)$ & 0.25 & Fixed \\
\hline & $\mathrm{A} / \mathrm{T}+\mathrm{T} / \mathrm{T}$ & $78 / 111$ & $67 / 110$ & $1.52(0.87-2.65)$ & 0.14 & Fixed \\
\hline & $\mathrm{T} / \mathrm{T}$ & $26 / 111$ & $24 / 110$ & $1.10(0.58-2.06)$ & 0.78 & Fixed \\
\hline & $\mathrm{A} / \mathrm{T}$ & $52 / 111$ & $43 / 110$ & $1.37(0.80-2.34)$ & 0.24 & Fixed \\
\hline
\end{tabular}

$\mathrm{OR}=$ odds ratio $; 95 \% \mathrm{CI}=$ confidence interval.

The positive associations between CASP gene family polymorphisms and LC susceptibility are shown in Figure 2.

\section{Publication bias}

Publication bias of the studies was assessed based on rs3834129 in the CASP-8 gene by Begger's funnel plot and the Egger linear regression test. The Egger linear regression test was used to measure the asymmetry of the funnel plot. The funnel plot of the studies included appeared to be symmetrical (Figure 3). The Egger test also showed that there was no statistical significance for all evaluations of publication bias $(\mathrm{P}=0.061)$. 


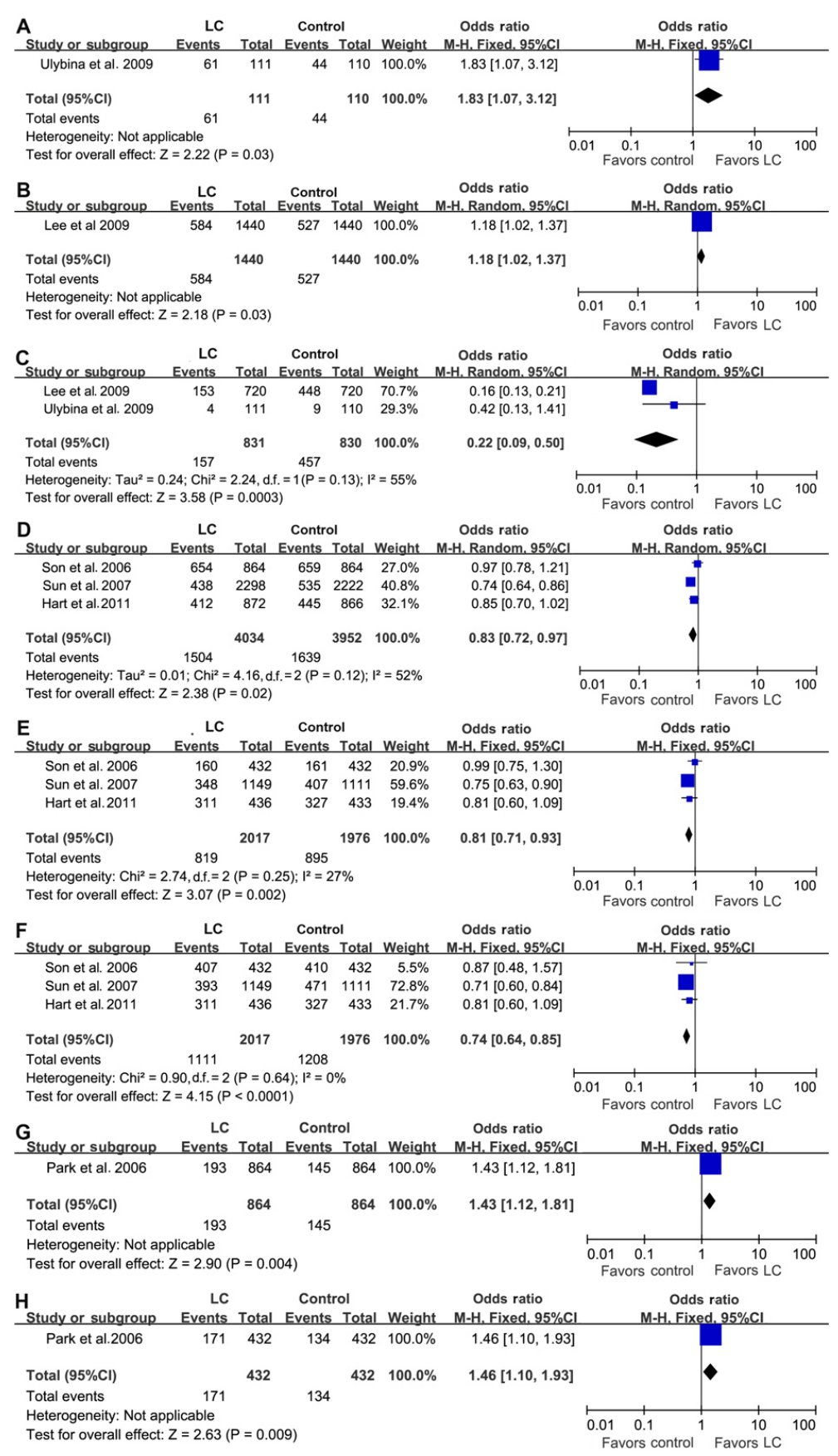

Figure 2. Positive associations between CASP gene family polymorphisms and lung cancer susceptibility. A. Heterozygote of rs507879; B. T allele of rs12415607; C. homozygote of rs2227310; D. del allele of rs3834129; E. heterozygote of rs3834129; F. del carrier of rs3834129; G. T allele of rs4645981; H. T carrier of rs4645981. LC = lung cancer; M.-H. = Mantel-Haenszel; $95 \% \mathrm{CI}=95 \%$ confidence interval. 


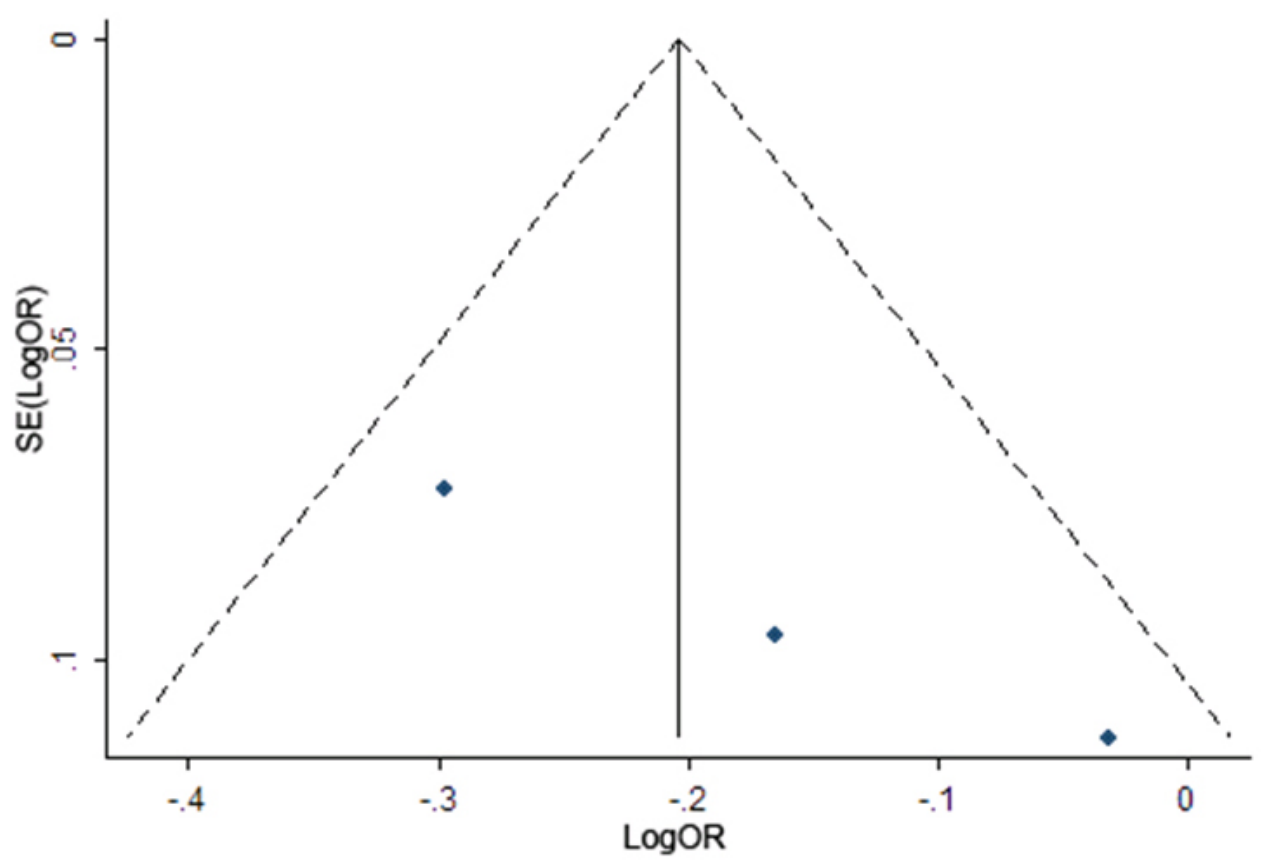

Figure 3. Begger's funnel plot of publication bias based on the association between rs 3834129 in the CASP- 8 gene and susceptibility to lung cancer.

\section{DISCUSSION}

LC ranks as the most malignant tumors around the world (D'Amico et al., 2010). It is estimated that 1.10 million people die from LC each year(Han et al., 2011). The most common form of LC is NSCLC, and the other is SCLC (Bandi et al., 2009). Smoking is the leading cause of lung cancer (Thorgeirsson et al., 2008). Besides that, some studies have found that genetic factors play an important role in the pathology of LC (El-Zein et al., 2012). It has been demonstrated that caspases are closely related to genetic susceptibility to cancers. The somatic mutations in CASP genes repress apoptosis leading to unwanted cell proliferation and anomalous cell survival (Srivastava et al., 2010). Caspases are a big family of highly conserved intracellular aspartate-specific cysteine proteases (Mittal et al., 2011). Polymorphism in CASP-9 gene has been shown to be associated with LC (Kesarwani et al., 2011). However, the clear connection between other genes in the caspase family and LC risk is not yet known.

In this meta-analysis, we quantitatively assessed the association between SNPs in CASP genes and LC risk. Finally, 7 case-control studies were included with a total of 1155 LC cases and 1120 healthy controls. We examined 7 CASP genes with 19 SNPs, including CASP$1,-2,-5,-7,-8,-9$, and -10 . The main meta-analysis results showed a significant association between CASP-5, $-7,-8$, and -9 and susceptibility to LC. There was a positive association between the heterozygote $(\mathrm{A} / \mathrm{G})$ of rs507879 in the CASP-5 gene and LC risk, which indicated that the heterozygote $(\mathrm{A} / \mathrm{G})$ of rs507879 may be a potential risk factor for LC. Moreover, the $\mathrm{T}$ allele of rs 12415607 in the CASP-7 gene and $\mathrm{T}$ allele and $\mathrm{T}$ carrier $(\mathrm{C} / \mathrm{T}+\mathrm{T} / \mathrm{T})$ of rs 4645981 
in the CASP-9 gene also may increase the risk of LC. Interestingly, we found that the homozygote $(\mathrm{G} / \mathrm{G})$ of rs2227310 in the CASP-7 gene, del allele, heterozygote (ins/del), and del carrier (ins/del + del/del) of rs3834129 in CASP-8 may decrease the risk of LC, suggesting that rs2227310 in the CASP-7 gene and rs3834129 in CASP-8 are protective factors against LC. In contrast, we found no significant associations between CASP-1 (rs501192), CASP2 (rs4647297), CASP-5 (rs523104), CASP-7 (rs1593766, rs2227310), CASP-8 (rs3769818, rs1045485), CASP-9 (rs4645978, rs4645980, rs4645982, rs1052571, rs1052576, rs2308950), and CASP-10 (rs13006529) (all P > 0.05) and LC risk.

Limitations in our meta-analysis should be addressed. First, because only the studies published were included in the meta-analysis, the relevant research articles are not many, and the sample size of this study was not large. Second, some relevant studies could not be included in our analysis due to incomplete raw data. Third, we were not able to address the sources of heterogeneity among all studies. In addition, although all cases and controls of each study were well defined with similar inclusion criteria, there might have been potential factors that were not taken into account and that may have influenced our results. Most important of all, our meta-analysis was based on unadjusted OR estimates because not all papers presented adjusted ORs or when they did, the ORs were not adjusted by the same potential confounders, such as ethnicity, gender, geographic distribution, etc. Given these considerations, additional investigation in these areas is needed, and our conclusions should be interpreted cautiously.

In conclusion, this meta-analysis of 7 case-control studies demonstrated that SNPs in CASP-5, $-7,-8$, and -9 are associated with susceptibility to LC. The heterozygote $(\mathrm{A} / \mathrm{G})$ of rs507879, $\mathrm{T}$ allele of rs 12415607, and $\mathrm{T}$ allele and $\mathrm{T}$ carrier $(\mathrm{C} / \mathrm{T}+\mathrm{T} / \mathrm{T})$ of rs 4645981 may be potential risk factors for LC, while the homozygote $(\mathrm{G} / \mathrm{G})$ of rs2227310 in the CASP-7 gene and del allele, heterozygote (ins/del), and del carrier (ins/del + del/del) of rs3834129 in CASP8 may decrease the risk of LC. Since few studies are available in this field and current evidence remains limited, it should be emphasized that there is a need to conduct large studies with an adequate methodological quality, properly controlling confounders to obtain valid results.

\section{ACKNOWLEDGMENTS}

We thank Liang Yuan (Department of Oncology, Liaoning Cancer Hospital and Institute) for her valuable contribution and for kindly revising the manuscript.

\section{REFERENCES}

Bandi N, Zbinden S, Gugger M, Arnold M, et al. (2009). miR-15a and miR-16 are implicated in cell cycle regulation in a $\mathrm{Rb}-d e p e n d e n t$ manner and are frequently deleted or down-regulated in non-small cell lung cancer. Cancer Res. 69: 5553-5559.

D’Amico A, Pennazza G, Santonico M, Martinelli E, et al. (2010). An investigation on electronic nose diagnosis of lung cancer. Lung Cancer 68: 170-176.

Du Y, Du Y and Zhao R (2005). Caspases and skin wound healing. Chin. J. Forensic Med. 20: 92-94.

El-Zein RA, Young RP, Hopkins RJ and Etzel CJ (2012). Genetic predisposition to chronic obstructive pulmonary disease and/or lung cancer: important considerations when evaluating risk. Cancer Prev. Res. 5: 522-527.

Han B, Xiu Q, Wang H, Shen J, et al. (2011). A multicenter, randomized, double-blind, placebo-controlled study to evaluate the efficacy of paclitaxel-carboplatin alone or with endostar for advanced non-small cell lung cancer. $J$. Thorac. Oncol. 6: 1104-1109.

Hart K, Landvik NE, Lind H, Skaug V, et al. (2011). A combination of functional polymorphisms in the CASP8, MMP1, IL10 and SEPS1 genes affects risk of non-small cell lung cancer. Lung Cancer 71: 123-129. 
Higgins JP and Thompson SG (2002). Quantifying heterogeneity in a meta-analysis. Stat. Med. 21: 1539-1558.

Kesarwani P, Mandal RK, Maheshwari R and Mittal RD (2011). Influence of caspases 8 and 9 gene promoter polymorphism on prostate cancer susceptibility and early development of hormone refractory prostate cancer. BJU Int. 107: 471-476.

Lee WK, Kim JS, Kang HG, Cha SI, et al. (2009). Polymorphisms in the Caspase7 gene and the risk of lung cancer. Lung Cancer 65: 19-24.

Long LY, Zhang GY, Zhou D, Liu LH, et al. (2008). Evidence-based bibliometric analysis of lung cancer research literature. Chin. J. Evid-based Med. 8: 1105-1111.

Lou Y, Fang CQ and Li JH (2007). A study on the expression of CASP9 gene and its polymorphism distribution in nonsmall cell lung cancer. Zhonghua Yi Xue Yi Chuan Xue Za Zhi. 24: 59-62.

MacPherson G, Healey CS, Teare MD, Balasubramanian SP, et al. (2004). Association of a common variant of the CASP8 gene with reduced risk of breast cancer. J. Natl. Cancer Inst. 96: 1866-1869.

Mittal RD, Srivastava P, Mittal T, Verma A, et al. (2011). Association of death receptor 4, Caspase 3 and 5 gene polymorphism with increased risk to bladder cancer in North Indians. Eur. J. Surg. Oncol. 37: 727-733.

Park JY, Park JM, Jang JS, Choi JE, et al. (2006). Caspase 9 promoter polymorphisms and risk of primary lung cancer. Hum. Mol. Genet. 15: 1963-1971.

Peters JL, Sutton AJ, Jones DR, Abrams KR, et al. (2006). Comparison of two methods to detect publication bias in metaanalysis. JAMA 295: 676-680.

Son JW, Kang HK, Chae MH, Choi JE, et al. (2006). Polymorphisms in the caspase- 8 gene and the risk of lung cancer. Cancer Genet. Cytogenet. 169: 121-127.

Srivastava K, Srivastava A and Mittal B (2010). Caspase-8 polymorphisms and risk of gallbladder cancer in a northern Indian population. Mol. Carcinog. 49: 684-692.

Stewart DJ (2010). Tumor and host factors that may limit efficacy of chemotherapy in non-small cell and small cell lung cancer. Crit. Rev. Oncol. Hematol. 75: 173-234.

Sun T, Gao Y, Tan W, Ma S, et al. (2007). A six-nucleotide insertion-deletion polymorphism in the CASP8 promoter is associated with susceptibility to multiple cancers. Nat. Genet. 39: 605-613.

Theodoropoulos GE, Gazouli M, Vaiopoulou A, Leandrou M, et al. (2011). Polymorphisms of caspase 8 and caspase 9 gene and colorectal cancer susceptibility and prognosis. Int. J. Colorectal Dis. 26: 1113-1118.

Thorgeirsson TE, Geller F, Sulem P, Rafnar T, et al. (2008). A variant associated with nicotine dependence, lung cancer and peripheral arterial disease. Nature 452: 638-642.

Ulybina YM, Kuligina ES, Mitiushkina NV, Rozanov ME, et al. (2009). Coding polymorphisms in Casp5, Casp8 and DR4 genes may play a role in predisposition to lung cancer. Cancer Lett. 278: 183-191.

Umar M, Upadhyay R, Kumar S, Ghoshal UC, et al. (2011). CASP8 -652 6N del and CASP8 IVS12-19G>A gene polymorphisms and susceptibility/prognosis of ESCC: a case control study in northern Indian population. J. Surg. Oncol. 103: 716-723.

Vaissière T, Hung RJ, Zaridze D, Moukeria A, et al. (2009). Quantitative analysis of DNA methylation profiles in lung cancer identifies aberrant DNA methylation of specific genes and its association with gender and cancer risk factors. Cancer Res. 69: 243-252.

Van De Water TR, Lallemend F, Eshraghi AA, Ahsan S, et al. (2004). Caspases, the enemy within, and their role in oxidative stress-induced apoptosis of inner ear sensory cells. Otol. Neurotol. 25: 627-632.

Vandenbroucke JP, von Elm E, Altman DG, Gøtzsche PC, et al. (2007). Strengthening the Reporting of Observational Studies in Epidemiology (STROBE): explanation and elaboration. Epidemiology 18: 805-835.

Viechtbauer W (2007). Hypothesis tests for population heterogeneity in meta-analysis. Br. J. Math. Stat. Psychol. 60: 29-60.

Wood DE, Eapen GA, Ettinger DS, Hou L, et al. (2012). Lung cancer screening. J. Natl. Compr. Canc. Netw. 10: $240-265$.

Yu CH, Kan SF, Shu CH, Lu TJ, et al. (2009). Inhibitory mechanisms of Agaricus blazei Murill on the growth of prostate cancer in vitro and in vivo. J. Nutr. Biochem. 20: 753-764.

Zhang L, Liu JL, Zhang YJ and Wang H (2011). Association between HLA-B*27 polymorphisms and ankylosing spondylitis in Han populations: a meta-analysis. Clin. Exp. Rheumatol. 29: 285-292.

Zhang X, Miao X, Sun T, Tan W, et al. (2005). Functional polymorphisms in cell death pathway genes FAS and FASL contribute to risk of lung cancer. J. Med. Genet. 42: 479-484.

Zhao H, Gu J, Xu H, Yang B, et al. (2010). Meta-analysis of the relationship between passive smoking population in China and lung cancer. Zhongguo Fei Ai Za Zhi. 13: 617-623.

Zintzaras E and Ioannidis JP (2005). Heterogeneity testing in meta-analysis of genome searches. Genet. Epidemiol. 28: 123-137. 